\title{
Strain relaxation index and diastolic function from echocardiography: the multi-ethnic study of atherosclerosis
}

\author{
Bharath Ambale Venkatesh ${ }^{1 *}$, Anderson C Armstrong ${ }^{2}$, Chia-Ying Liu', Andre Almeida ${ }^{2}$, Eui-Young Choi ${ }^{2}$, \\ Boaz D Rosen ${ }^{2}$, Marcelo Nacif ${ }^{3}$ Colin O Wu', David A Bluemke³, Joao A Lima²
}

From 16th Annual SCMR Scientific Sessions

San Francisco, CA, USA. 31 January - 3 February 2013

\section{Background}

A novel strain relaxation index (SRI) is introduced to assess diastolic function by CMR, using myocardial deformation during LV relaxation. We investigate how SRI relates to standard diastolic parameters by echocardiography (echo). We also relate SRI to mass to volume ratio (MVR) by CMR, which is seen to increase in diastolic dysfunction. SRI accounts for both very early myocardial relaxation and tissue compliance.

\section{Methods}

Participants from the Multi-Ethnic Study of Atherosclerosis (MESA) who underwent echo and tagged CMR on the same day at the Johns Hopkins Hospital (2006-2008) were included. Harmonic phase analysis was used to compute mid-ventricular mid-wall circumferential strains and strain rates (Figure 1). SRI was calculated as the difference between post-systolic and systolic times of the strain peaks (indicator of myocardial relaxation), divided by the early diastolic strain rate peak (measure of tissue compliance). It was normalized by the total relaxation time, calculated as the difference between the RR interval and the systolic interval. CMR LV mass and end-diastolic volumes were assessed by the Simpson method. Tissue Doppler echo assessed lateral and septal diastolic tissue velocity ( $\mathrm{e}^{\text {' }}$ wave). For E/e' calculation, echo pulse-wave Doppler E peak was divided by the average of sep and lat e' waves. Diastolic function was rated from 0 to 3 , according to the

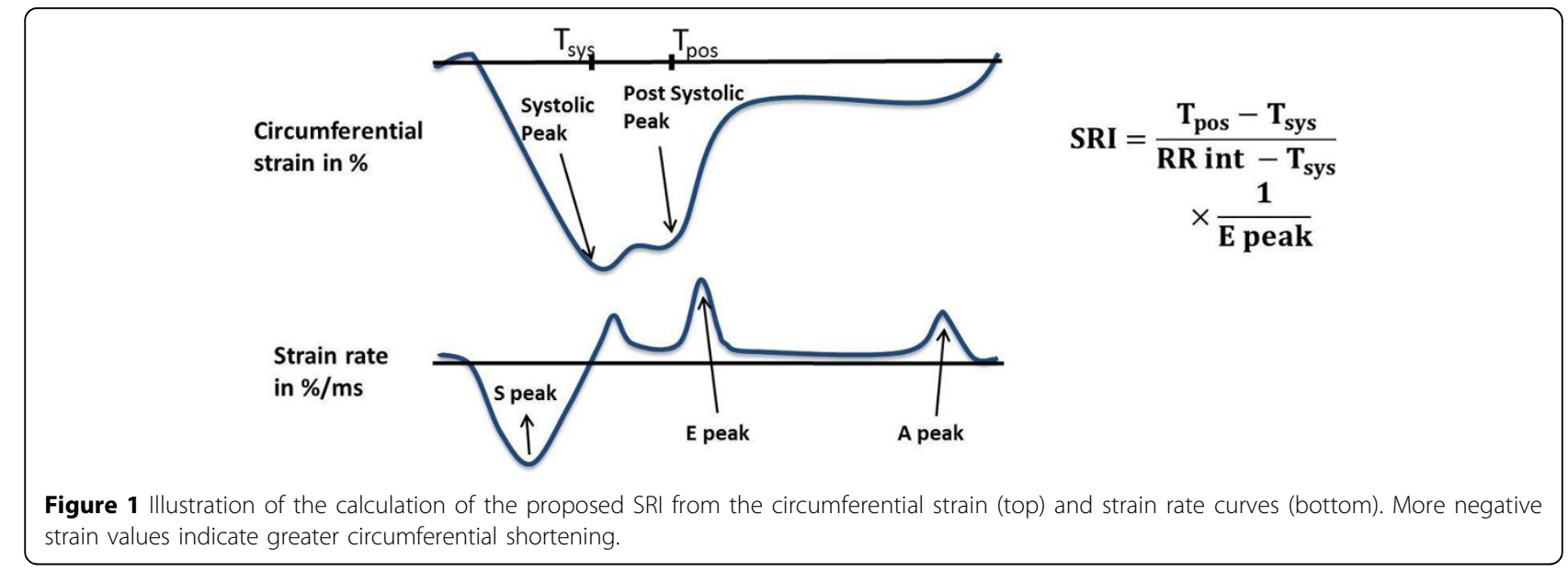

'Radiology, Johns Hopkins Hospital, Baltimore, MD, USA

Full list of author information is available at the end of the article

(c) 2013 Venkatesh et al; licensee BioMed Central Ltd. This is an Open Access article distributed under the terms of the Creative 

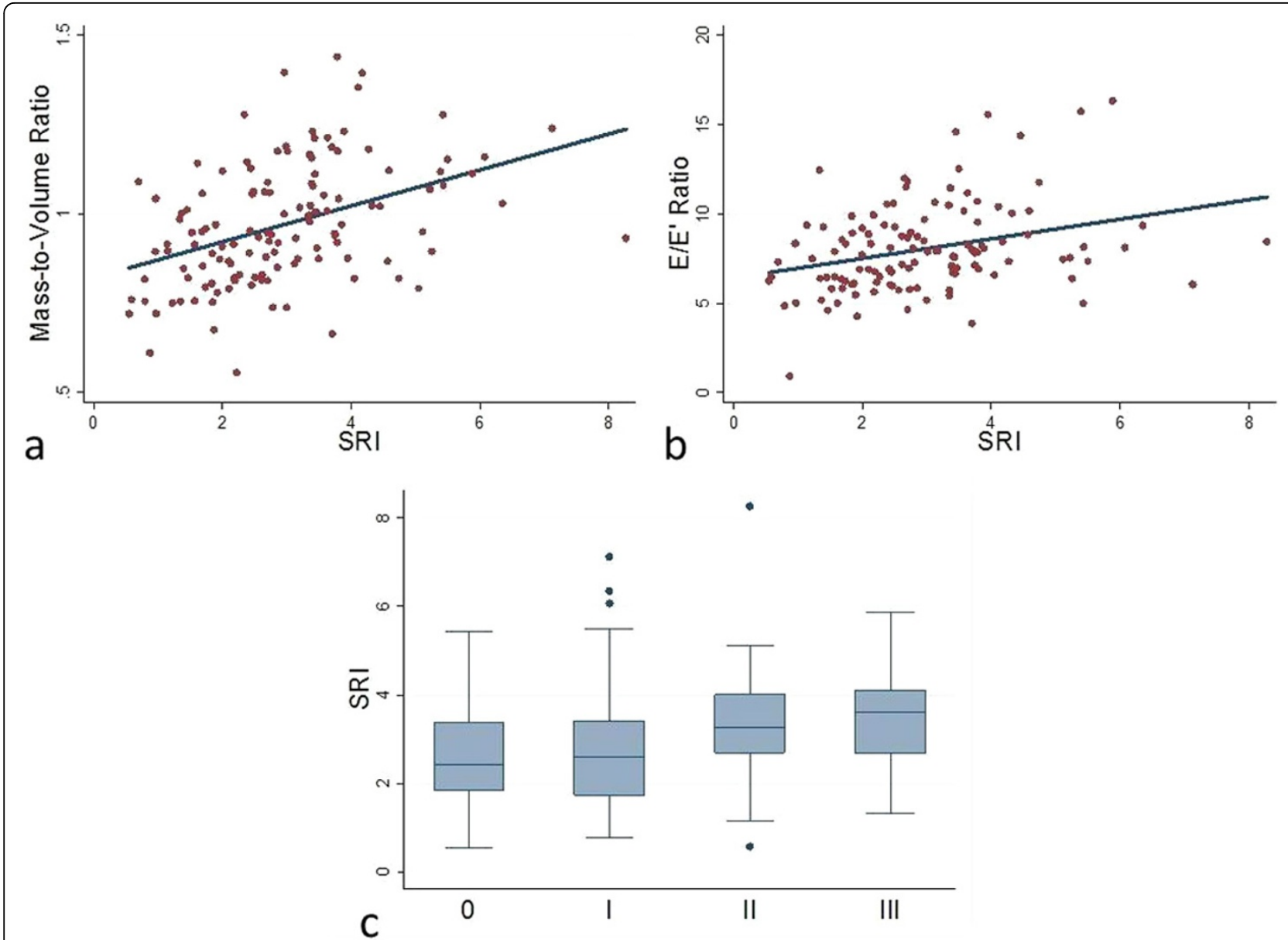

Figure 2 Correlation of SRI and mass-to-volume ratio (a) and E/e' ratio (b). Box plot of SRI measures across grades of diastolic function (c).

number of matched criteria: (1) septal e' $<8 \mathrm{~cm} / \mathrm{s}$; (2) lateral e'< $10 \mathrm{~cm} / \mathrm{s}$; and (3) E/e' $\geq 10$. Pearson's correlation compared SRI to MVR and echo parameters, and ANOVA tested differences across diastolic ratings.

\section{Results}

We included 125 participants, age $61 \pm 8$ years; $41 \%$ males; 56\% White, 44\% African-American; 50\% hypertensive; $14 \%$ diabetic. Mean values for MVR, sep e', lat e', E/e', and SRI were $0.97 \pm 0.17 \mathrm{~g} / \mathrm{mL} ; 9.1 \pm 2.3 \mathrm{~cm} / \mathrm{s}$; $10.6 \pm 3.1 \mathrm{~cm} / \mathrm{s} ; 8.0 \pm 2.5$; and $2.94 \pm 1.4 \mathrm{~ms}$, respectively. SRI correlated positively to MVR $(r=0.42, p<0.001$, Figure $2 \mathrm{a})$ and $E / \mathrm{e}^{\prime}(\mathrm{r}=0.31, \mathrm{p}<0.001$, Figure $2 \mathrm{~b})$, but negatively to e' values (septal $\mathrm{r}=-0.28, \mathrm{p}<0.001$; lateral $\mathrm{r}=-0.22, \mathrm{p}=0.01)$. SRI showed increasing trend across diastolic function ratings $(\mathrm{p}=0.03$, Figure $2 \mathrm{c})$.

\section{Conclusions}

SRI, a novel indicator of diastolic function, as measured from tagged CMR showed good relation to MVR by
CMR and standard echo parameters of diastolic function.

\section{Funding}

NHLBI grant - HL066075.

\section{Author details}

${ }^{1}$ Radiology, Johns Hopkins Hospital, Baltimore, MD, USA. ${ }^{2}$ Cardiology, Johns Hopkins Hospital, Baltimore, MD, USA. ${ }^{3}$ Radiology and Imaging Sciences, National Institutes of Health, Bethesda, MD, USA. ${ }^{4}$ National Institutes of Health, Bethesda, MD, USA.

Published: 30 January 2013

doi:10.1186/1532-429X-15-S1-E75

Cite this article as: Venkatesh et al: Strain relaxation index and diastolic function from echocardiography: the multi-ethnic study of atherosclerosis. Journal of Cardiovascular Magnetic Resonance 2013 15(Suppl 1):E75. 